\title{
CUIDADO E RECUPERAÇÃO DO IDOSO COM FRATURA DECORRENTE DE QUEDA NA PERSPECTIVA DO CUIDADOR FAMILIAR
}

\author{
CARE AND RECOVERY OF THE ELDERLY WITH \\ FALL-RELATED FRACTURE IN THE FAMILY \\ CAREGIVER'S PERSPECTIVE
}

\section{RECUPERACIÓN Y CUIDADO DE LOS ANCIANOS CON FRACTURA DEBIDO A UNA CAÍDA EN LA PERSPECTIVA DEL CUIDADOR FAMILIAR}

\author{
Camila Moraes Garollo ${ }^{1}$ \\ Sonia Silva Marcon $^{2}$ \\ Elen Ferraz Teston ${ }^{3}$ \\ Helen Cristina Bernardes Barbosa ${ }^{4}$ \\ Josane Rosenilda da Costa ${ }^{5}$ \\ Ivi Ribeiro Back ${ }^{6}$ \\ Patrícia Chatalov Ferreira ${ }^{7}$
}

\begin{abstract}
Como citar este artigo: Garollo CM, Marcon SS, Teston EF, Barbosa HCB, Costa JR, Back IR, Ferreira PC. Cuidado e recuperação do idoso com fratura decorrente de queda na perspectiva do cuidador familiar. Rev baiana enferm. 2020;34:e34778.

Objetivo: apreender a perspectiva do cuidador familiar sobre o cuidado e a recuperação do idoso com fratura decorrente de queda. Método: estudo descritivo e exploratório realizado com 15 cuidadores familiares de idosos no município de Borrazópolis, Paraná, Brasil, nos meses de junho e julho de 2018, mediante entrevistas semiestruturadas submetidas à análise de conteúdo, modalidade temática. Resultados: emergiram quatro categorias temáticas: equipe de enfermagem apoiando familiares cuidadores de idosos com fratura; imobilização de membro ou restrição ao leito como condição geradora de dependência; peculiaridades do cuidado ao idoso com fratura; e religiosidade/ espiritualidade fortalecendo o cuidado cotidiano. Conclusão: na perspectiva do cuidador familiar, o cuidado e a recuperação do idoso com fratura decorrente de queda envolve dedicação, alterações no cotidiano pessoal e familiar e sobrecarga para o cuidador, além de dificuldades decorrentes do despreparo e da não aceitação da condição de dependência por parte do idoso.
\end{abstract}

Descritores: Cuidadores. Idoso. Acidentes por Quedas. Reabilitação. Enfermagem.

Objective: to know the family caregiver's perspective on the care and the recovery of the elderly with a fall-related fracture. Method: descriptive and exploratory study conducted with 15 family caregivers of the elderly in the municipality of Borrazópolis, Parana State, Brazil, in the months of June and July 2018, through semi-structured

\footnotetext{
Estudante de Enfermagem. Universidade Estadual de Maringá. Maringá, Paraná, Brasil. camilagarollo@gmail.com. https://orcid.org/0000-0002-9| I I-9992. Enfermeira. Doutora em Filosofia. Professora na Universidade Estadual de Maringá. Maringá, Paraná, Brasil. https://orcid.org/0000-0002-6607-362X.

Enfermeira. Doutora em Enfermagem. Universidade Federal de Mato Grosso do Sul. Campo Grande, Mato Grosso do Sul, Brasil. https://orcid.org/0000-000 I-6835-0574.

Estudante de Enfermagem. Universidade Estadual de Maringá. Maringá, Paraná, Brasil. https://orcid.org/0000-0003-|4|8-645 |.

Enfermeira. Mestre em Enfermagem. Universidade Estadual de Maringá. Maringá, Paraná, Brasil. https://orcid.org/0000-0003-0369-977X.

Enfermeira. Doutora em Ciências da Saúde. Professora no Centro Universitário de Maringá. Maringá, Paraná, Brasil. https://orcid.org/0000-0002-7867-8343.

Enfermeira. Especialista em Enfermagem nas Emergências. Universidade Estadual de Maringá. Maringá, Paraná, Brasil. https://orcid.org/0000-000 I-9409-5888.
} 
interviews submitted to thematic content analysis. Results: four thematic categories emerged: nursing team supporting family caregivers of the elderly with fracture; limb immobilization or restriction to bed as a dependency-generating condition; peculiarities of the care with the elderly with fracture; and religion/spirituality strengthening daily care. Conclusion: in the family caregiver's perspective, the care and the recovery of the elderly with a fall-related fracture involve dedication, changes in personal and family life and burden to the caregiver, besides difficulties arising from the lack of training and non-acceptance of the dependency condition by the elderly.

Descriptors: Caregivers. Aged. Accidental Falls. Rehabilitation. Nursing.

Objetivo: comprender la perspectiva del cuidador familiar en el cuidado y la recuperación de los ancianos con fractura debido a la caída. Método: estudio descriptivo y exploratorio realizado con 15 cuidadores familiares de ancianos en el municipio de Borrazópolis, Paraná, Brasil, en los meses de junio y julio de 2018, a través de entrevistas semi-estructuradas sometidas al análisis de contenido temático. Resultados: cuatro categorías temáticas surgieron: apoyo del equipo de enfermería a los cuidadores familiares de ancianos con fractura; inmovilización de extremidades o restricción a la cama como una condición que genera dependencia; las peculiaridades de los ancianos con fractura; y religión/espiritualidad fortaleciendo la rutina del cuidado. Conclusión: en la perspectiva del cuidador familiar, el cuidado y la recuperación de los ancianos con una fractura debido a la caída implican la dedicación, los cambios en la vida personal y familiar y la sobrecarga para el cuidador, además de las dificultades derivadas de la falta y no aceptación de la condición de dependencia por parte de los ancianos.

Descriptores: Cuidadores. Anciano. Accidentes por Caídas. Rehabilitación. Enfermería.

\section{Introdução}

A senescência, etapa natural do ciclo de vida humana, é caracterizada por mudanças físicas, biológicas e psicológicas. Em consequência da transição demográfica, estima-se que, até 2050, o número de pessoas com 60 anos ou mais chegará a dois bilhões, representando um quinto da população mundial ${ }^{(1)}$.

Nessa etapa da vida, um dos eventos que frequentemente impossibilitam o indivíduo de viver com autonomia é a fratura de algum segmento corporal decorrente de queda. Trata-se de um evento involuntário, originado, na maioria das vezes, na perda do equilíbrio. Salienta-se que as maiores taxas de ocorrência e de mortalidade por esta causa ocorrem em pessoas com mais de $60 \operatorname{anos}^{(2)}$. A fratura do fêmur é bastante frequente nessa população, interferindo diretamente na mobilidade do idoso e na necessidade de acompanhamento/supervisão de outras pessoas, uma vez que gera necessidade de restrição ao leito ${ }^{(1-2)}$.

Contudo, tornar-se dependente de cuidados, ainda que temporariamente, reflete negativamente na qualidade de vida do idoso ${ }^{(3)}$. Isto porque a queda, muitas vezes, ocorre em pessoas que até então eram totalmente independentes e o fato de passarem abruptamente a necessitar de um cuidador não é uma condição aceita com facilidade.

Nesse contexto, o ato de cuidar inclui ajudar e, por vezes, realizar cuidados básicos, como higiene corporal, nutrição, eliminações fisiológicas, auxílio na locomoção e conforto, além de suporte emocional, estímulo à interação social e assistência pessoal de acordo com as necessidades sentidas e observadas ${ }^{(4)}$. A prestação de cuidados às pessoas idosas é, em grande parte, efetuada por cuidadores familiares, sobretudo pelas mulheres - esposas, filhas e noras - que, muitas vezes, se esforçam para conciliar atividades relacionadas a sua vida familiar, pessoal e laboral com a responsabilidade de cuidar de uma pessoa idosa dependente ${ }^{(5)}$.

No entanto, a função assumida pode ser permeada por dúvidas, incertezas e sofrimento, o que gera impacto não só na qualidade do cuidado prestado como também na qualidade de vida de toda a família. Diante do exposto, questiona-se: Como o cuidador percebe a condição de dependência do idoso após a queda? Quais fatores influenciam na recuperação do idoso com fratura decorrente de queda? 
Para responder a esses questionamentos, definiu-se como objetivo deste estudo apreender a perspectiva do cuidador familiar sobre o cuidado e a recuperação do idoso com fratura decorrente de queda.

\section{Método}

Trata-se de estudo descritivo exploratório, de natureza qualitativa, realizado em Borrazópolis, Paraná, município de pequeno porte (pouco mais de 6.000 mil habitantes) localizado no Sul do Brasil. A rede de atenção à saúde do município conta com duas Unidades Básicas de Saúde (UBS), ambas com equipe da Estratégia Saúde da Família (ESF), Clínica da Mulher para assistência pré-natal e um hospital público de pequeno porte (35 leitos).

Participaram do estudo cuidadores familiares de idosos residentes no município e que sofreram fratura decorrente de queda nos anos de 2016, 2017 e 2018. Para localização dos idosos foi solicitado às enfermeiras e agentes comunitárias de saúde (ACS) das duas UBS o levantamento daqueles que atendiam aos critérios de elegibilidade. Como critérios de inclusão, foram definidos: pessoas com 18 anos ou mais e ser cuidador familiar principal de idoso que sofreu fratura após queda ocorrida no período previamente definido. Como critério de exclusão foi estabelecida a não localização do cuidador após pelo menos cinco tentativas realizadas em dias e horários distintos (cinco casos). Ressalta-se que, antes da indicação, os ACS entraram em contato com os cuidadores para informar sobre o estudo e solicitar permissão para fornecer o contato telefônico.

Os dados foram coletados nos meses de junho e julho de 2018, mediante entrevistas semiestruturadas, previamente agendadas por telefone, pela pesquisadora principal. Foram realizadas em dias, horários e locais definidos pelos participantes, sendo cinco na própria residência do cuidador e dez nos domićlios dos idosos. Elas tiveram duração média de 40 minutos, foram áudio gravadas mediante o consentimento dos participantes e guiadas pelas seguintes questões: "Conte-me como ocorreu a queda", "Como foi/está sendo o processo de recuperação do idoso?" e "Como foi/está sendo para você cuidar do idoso dependente de cuidados?" Foi também utilizado um roteiro com questões abordando características sociodemográficas do idoso e do cuidador.

Todas as entrevistas foram transcritas na íntegra e preferencialmente no mesmo dia de sua realização. Antes de iniciar o processo analítico, as falas foram editadas, retirando-se os vícios de linguagem e corrigidos erros gramaticais, a fim de proporcionar maior fluidez à leitura das entrevistas, sem, contudo, alterar seu sentido e conteúdo ${ }^{(6)}$.

O material transcrito foi submetido à análise de conteúdo, modalidade temática, seguindo as fases operacionais fundadas na constituição do corpus, leitura flutuante, exploração do material, composição das unidades de registro correspondentes à unidade de significação (recorte das falas), com posterior classificação para compor as categorias segundo critério semântico, isto é, os conteúdos com particularidades semelhantes foram agrupados, o que culminou em categorias temáticas ${ }^{(6)}$. No processo de análise foram identificadas 85 unidades de registro que, agrupadas, permitiram a identificação de 15 subcategorias e 4 categorias, conforme Figura 1. 
Figura 1 - Organograma do processo de definição das categorias temáticas

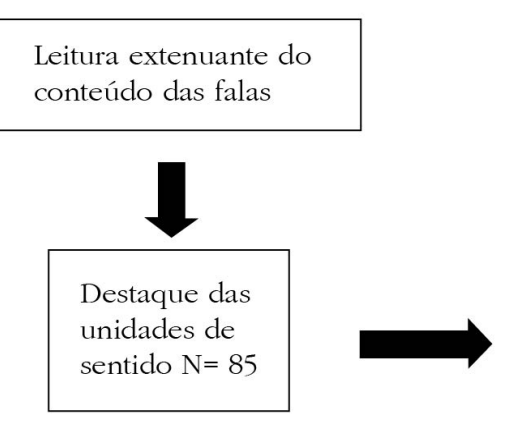

\begin{tabular}{|l|}
\hline \multicolumn{1}{|c|}{$\begin{array}{c}\text { Emergiram quatro } \\
\text { categorias: }\end{array}$} \\
- Equipe de enfermagem \\
apoiando familiares cuidadores \\
de idosos com fratura \\
- Imobilização de membro ou \\
restrição ao leito como condição \\
geradora de dependência \\
- Peculiaridades do cuidado ao \\
idoso com fratura \\
- Religiosidade/espiritualidade \\
fortalecendo o cuidado cotidiano \\
\hline
\end{tabular}

Fonte: Elaboração própria.

O estudo foi desenvolvido em consonância com as diretrizes disciplinadas pela Resolução n. 466/12 do Conselho Nacional de Saúde/Ministério da Saúde. Seu projeto foi aprovado pelo Comitê Permanente de Ética em Pesquisa Envolvendo Seres Humanos (COPEP) da instituição signatária, (Parecer n. 2.698.673). Todos os participantes manifestaram sua anuência em participar do estudo, assinando o Termo de Consentimento Livre e Esclarecido. Para resguardar-lhes a identidade, os extratos de seus relatos estão identificados pela letra "C", indicativa de cuidador, um número, que informa a ordem de realização da entrevista, seguido da palavra indicativa da relação com o idoso.

\section{Resultados}

Participaram do estudo 15 cuidadores dos quais 13 eram casados e 2 viúvos, sendo 13 do sexo feminino - 9 filhas, 2 sobrinhas, 1 nora e 1 amiga. Os cuidadores homens eram 1 esposo

\section{Agrupamento temático em 15 subcategorias:}

- Experiência anterior com outros idosos acidentados por quedas;

- Principais causas dos acidentes por quedas;

- Busca por informação sobre o cuidado para uma boa recuperação;

- Apoio de familiares;

- Importância da afetividade;

- Conhecimento sobre medidas preventivas de quedas;

- Valorização da participação da família para a recuperação do idoso;

- Religiosidade/espiritualidade como motivação para a reabilitação;

- Compreensão da perda de autonomia do idoso;

- Participação da família no processo de recuperação;

- Relevância dos profissionais diante as circunstâncias do idoso;

- Mudanças da rotina diária do cuidador;

- Dificuldades enfrentadas após a queda;

- Medo de que os idosos caiam novamente;

- Mobilização da família na organização

da rotina de vida; e 1 filho. Dez participantes relataram que era a primeira vez que atuavam como cuidadores

Os idosos, por sua vez, tinham idade entre 60 e 95 anos (média 77,26 anos), sendo 13 do sexo feminino. O segmento corporal afetado pela fratura mais frequente foi o fêmur. O tratamento instituído para 11 idosos foi cirúrgico enquanto, para os outros 4, foi conservador. O tempo de recuperação variou de 2 a mais de 13 meses e 10 idosos foram submetidos a tratamento fisioterapêutico.

A partir da leitura extenuante das entrevistas, identificou-se que a experiência do cuidador é marcada por uma trajetória, a qual permitiu a identificação das quatro categorias descritas a seguir.

\section{Equipe de enfermagem apoiando familiares cuidadores de idosos com fratura}

Observa-se que, na perspectiva dos cuidadores familiares, os profissionais que compunham 
a equipe de enfermagem tinham papel importante no processo de recuperação do idoso que sofreu fratura, ao realizarem, orientarem e auxiliarem na execução de cuidados.

Eu só pedia ajuda da equipe de enfermagem, que acolbia e nos ajudava. (C1, Filha).

A equipe de enfermagem ensinavam a fazer de tudo para proporcionar uma boa qualidade de vida para minha mãe. (C2, Filha).

Nós tivemos um acompanhamento muito grande com os enfermeiros que faziam as visitas e nos ensinavam todos os procedimentos a serem realizados dali para frente. (C3, Filha).

As unidades de significado mostraram existir uma relação de proximidade entre os profissionais de saúde e a família/cuidadores do idoso em situação de fragilidade/doença.

Não sei se isso facilitou, mas não tem nem o que reclamar, foi $100 \%$ tudo bem aproveitado. Desde o apoio de como organizar o quarto até como agir a partir daquela situação. Quando ela chegou do hospital, a equipe da enfermagem, no primeiro mês, visitava três vezes na semana e o médico, de 15 em 15 dias. (C3, Filha).

O médico foi um excelente profissional, mas, da equipe de saúde que fazia a visita, era o enfermeiro [nome] que sempre estava à disposição com todo aquele cuidado. Sempre que precisava de alguma coisa, era só pedir para ele. Foi um apoio essencial para a recuperação. (C6, Amiga).

O pessoal do Sistema Único de Saúde ajudou muito. O acompanhamento com a equipe de saúde foi importante para uma boa recuperação, principalmente para enfrentar as dificuldades que não estávamos acostumados. (C7, Filho).

De acordo com os cuidadores, os profissionais de enfermagem orientaram a implementação de cuidados e hábitos que tinham por objetivo diminuir riscos de novas quedas e promover um envelhecimento sadio.

As enfermeiras faziam curativos, nos orientavam muito bem sobre as medidas a serem tomadas. (C12, Filha).

Os idosos têm uma tendência a não querer fazer as coisas e, junto com os enfermeiros serem persistentes, colabora para um bom envelhecimento e superação das dificuldades. (C15, Filha).

As unidades de significado desta categoria mostraram que os profissionais de saúde, em especial aqueles que compunham a equipe de enfermagem, constituíam importante elemento na rede de apoio dos cuidadores familiares, à medida que os auxiliavam no cuidado e na recuperação do idoso que sofreu fratura.

\section{Imobilização de membro ou restrição ao leito como condição geradora de dependência}

Para todos os idosos deste estudo, a imobilização de membro ou a restrição ao leito durante algum tempo, como parte do tratamento prescrito, alterou a locomoção e a capacidade funcional e, por consequência, reduziu sua autonomia. O tempo de restrição ao leito ou de imobilização do membro afetado variou de semanas a meses e foi maior entre aqueles que passaram por procedimento cirúrgico, visto ter sido necessário tempo para a recuperação cirúrgica e para a reabilitação, por meio de tratamento fisioterapêutico.

O tempo que o idoso ficou restrito ao leito ou com um de seus membros imobilizado desencadeou a necessidade de um cuidador e a sobrecarga para a pessoa que assumiu esta função.

[...] depois eu fazia tudo para ela, pois ela fazia praticamente nada, a não ser repousar. (C3, Filha).

[...] ele dependia de alguém para tudo. (C9, Nora).

Ela era totalmente dependente da gente [...] dependia de alguém para tudo. (C15, Filha).

Ela se tornou mais limitada [...] ficou dependente e perdeu a autonomia da vida. (C6, Amiga).

Destaca-se que, para sete idosos, a imobilização como forma de tratamento foi a única condição geradora de dependência, visto que, antes da fratura, eram totalmente independentes. Foi uma mudança de vida. Foi muito chocante o que
uma queda acarretou e causou em nossas vidas, pois ti-
vemos que mudar toda nossa vida. Não tem como não
dizer que não mudaria. (C2, Filha).

Por conta da restrição ao leito foi difícil a aceitação dela, por se tornar dependente de alguém [...] antes muito independente e de repente, dependente de alguém para tudo. (C3, Filha).

Ficar em cima de uma cama dependendo de alguém para tudo é difícil para ela. É possível ver a tristeza no olhar, por não ser mais independente. (C11, Sobrinha).

Ao descreverem os cuidados realizados no âmbito domiciliar para a recuperação do idoso, os cuidadores mostraram que abarcavam mais do que o atendimento de necessidades básicas, como higiene e alimentação ou a recuperação da saúde, mediante o uso correto do medicamento. 
Isto porque, tinham como propósito, além da recuperação da saúde, o bem-estar físico, mental e a qualidade de vida do idoso.

Eu cuidei dela, dava banho, comida, sorvete, banana amassadinha, água, suco e, enfim, dava todos os remédios nos horários certos [...] (C5, Filha).

Eu sempre fazia o que poderia trazer bem-estar para ela e qualidade de vida. Tudo era feito para que sua recuperação pudesse ser rápida. (C6, Amiga).

Era feito uma escala para cada semana com um filho. Então, todos sabiam os horários de medicamento, de banho, de troca. Todos faziam absolutamente a mesma coisa para não atrapalhar a qualidade de vida dela. Tinha horário para tudo. (C2, Filha).

Eu gosto de ver ela bem. Abri mão de muita coisa, para proporcionar os melhores cuidados para ela, podendo oferecer qualidade de vida, mesmo com o envelhecimento e a fratura. (C11, Sobrinha).

As unidades de significado incluídas nesta categoria mostraram que o esforço empreendido pelo cuidador era fundamental para a manutenção das atividades básicas de vida do idoso e sua recuperação após episódio de queda. Contudo, esse esforço era gerador de sobrecarga física e emocional para o cuidador.

\section{Peculiaridades do cuidado ao idoso com fratura}

De acordo com os participantes, eram muitas as dificuldades enfrentadas para cuidar de um idoso com dependência decorrente de fratura. Algumas delas relacionavam-se ao próprio modo de ser do idoso, que tinha dificuldade de aceitar ser cuidado; outras decorriam da logística do processo de cuidar.

Ela não aceitava que dependia da gente. Queria fazer tudo sozinha e, claro, não conseguia. Queria fazer a comida com um braço só, derrubava as coisas e dai falava: porque Deus não me leva de uma vez?... era uma luta diária, principalmente na hora do banho. (C2, Filha).

A perna ficou com sequelas, ficou torta. Então, para limpar a virilha, por exemplo, ela não conseguia abrir muito, era muito dificultoso. (C15, Filha).

[...] é difícil, porque dar banho em um idoso já é difícil, ainda mais fraturado. É complicado, demandava muito esforço [...] Com aquele braço, ela não conseguia fazer nada. (C3, Filha)

Uma dificuldade peculiar no cuidado ao idoso está relacionada ao pudor em expor partes íntimas durante o banho ou na troca de fraldas.
Ressalta-se que, nesses casos, os cuidadores também sentiam dificuldade/vergonha.

$$
\begin{aligned}
& \text { A maior dificuldade era a vergonha de ver ele pelado, de } \\
& \text { ter que dar o banho. (C9, Nora). } \\
& \text { No banho [...] mostrar as partes intimas era difícil para ela } \\
& \text { [...] idosa, durante as trocas de fraldas também [...] era difi- } \\
& \text { cil ver a mãe da gente naquele estado na cama. (C12, Filha). }
\end{aligned}
$$

As dificuldades encontradas no cotidiano acentuavam a sobrecarga física, emocional e social, desencadeando estresse no cuidador.

Ela era dependente de nós e não nós dela. Dependia 24 boras do nosso cuidado para tudo. (C2, Filha).

Pior que ele dependia de alguém para tudo... Não tenho vida particular mais, todo o meu tempo fica em torno do cuidado dele. (C9, Nora).

O cuidado era totalmente dependente de mim [...] e tudo que precisava dependia de mim. Isso fez com que ela perdesse sua autonomia. (C14, Filha).

Eu tinha que cuidar dela, tinha de dar banbo, tinha que ajudar em tudo [...] ela me chamava para tudo [...] ficou muito corrido, pois minha vida já é corrida. Tenho casa, filbo, marido e, depois da queda, mais ela [...] ficou bem puxado. (C3, Filha).

As várias mudanças no cotidiano dos cuidadores desencadearam implicações importantes na vida familiar.

Somos três irmãs e tivemos que adaptar o nosso trabalho, nossa casa, nossa família, nossos hábitos e costumes. Tudo teve que ser mudado, tudo, para esse novo processo de recuperação. (C2, Filha).

Qualquer coisa de saúde ou mudança que acontecia na vida dela, eu tinha que estar atenta. Dava insegurança de tamanha responsabilidade. Isso mudava minha vida. (C15, Filha).

Cheguei à uma conclusão com o meu marido, que levaria ela para dentro da minha casa. Eu sabia que minha vida iria mudar [...] parei de trabalhar, meu ritmo de sair de casa já não era mais o mesmo. Se eu tinha que sair, fazer alguma coisa, meu marido ficava fazendo companhia para ela. Por isso, tamanha mudança na minha vida e na do meu esposo [...] meu marido teve muita paciência pelo fato da nossa vida ter mudado completamente quando eu trouxe a minha tia. (C11, Sobrinha).

As unidades de contexto desta categoria mostraram que cuidar de um idoso com dependência de cuidados em decorrência de fratura vai além de exercer uma função, pois os cuidadores demonstraram que abdicaram de sua vida social e/ou sacrificaram/alteraram sua vida profissional em prol da recuperação dos idosos. Ademais, as peculiaridades do cuidado cotidiano culminaram em estresse e implicações no cotidiano familiar, além de sobrecarga. 
Religiosidade/espiritualidade fortalecendo o cuidado

O cuidador demonstrou consciência de sua missão e moldou-se às exigências inerentes do processo de cuidar, sobretudo de um idoso. Para eles, este aperfeiçoamento e as demandas contínuas foram importantes para aumentar o vínculo entre a tríade: cuidador-idoso-família. A reflexão acerca de seu papel trouxe à tona questões relacionadas aos valores e propósito humanos, com destaque para a religiosidade/ espiritualidade. Acreditamos em Deus [...] a cirurgia dela foi feita, não
pela mão do bomem e sim por um milagre de Deus.
Passava mil coisas pela minha cabeça. Ficava pen-
sando se minha esposa ia se recuperar [...] eu sentava
no canto, rezava e pedia a Deus para dar força e que
nunca faltasse esperança [...] Eu me agarrei à fé e à for-
ça de vontade para ela poder viver bem, aí eu passava
confiança e enfrentávamos as dificuldades juntos [...]
Fizemos um juramento perante Deus: Juntos, na saúde
e na doença, na alegria e na tristeza. Então um cuida
do outro. Companheirismo é muito importante diante
das dificuldades. (C4, Esposo).

Contava com o apoio da religião, porque só Deus para sustentar a gente naqueles momentos de angústia e sofrimento. Não tem como explicar. (C15, Filha).

Ter fé, independente da religião, e fazer as orações [...] Manter o foco do começo ao fim para cuidar, sempre estando bem, alegre e graças a Deus isso não é mérito só nosso, e sim de todos os que nos ajudaram. (C2, Filha).

Tanto que eu pensava: Deus colocou ela nas minhas mãos para eu cuidar, pois Ele sabia que eu tinha competência para cuidar e lutar pela saúde dela. (C11, Sobrinha).

Eu me agarrei à fé e à força de vontade para ela poder viver bem. (C3, Filha).

Observa-se, nas unidades de contexto, que a religiosidade/espiritualidade aliada à união da família foi fundamental no processo de cuidar, pois fortaleceu o cuidador e o sensibilizou para prestar um cuidado com mais afetividade, pautado em valores humanos, além de sensibilizar a família sobre a importância de maior aproximação com o idoso.

Tem que ter amor e carinho para cuidar de uma pessoa, independente se quebrou um braço ou uma perna, se é mais velho. Porque a pessoa está debilitada não porque quer, mas sim por um acidente que podia ter sido evitado. (C6, Amiga).

Acredito que todo esse comprometimento familiar e demonstração de amor por ela contribuiu para ela ir se recuperando bem. (C2, Filha).
O que facilitou a recuperação foi a união da família, a persistência e a demonstração da importância dela em nossas vidas. (C14, Filha).

De acordo com as unidades de contexto, embora o processo de cuidar envolvesse sofrimento e abnegação, em alguns casos permitiu o resgate do vínculo entre cuidador-idoso-família. Mostraram ainda que o cuidador encontrava, na religiosidade/espiritualidade, forças e incentivo para cuidar. Desse modo, o comprometimento com essa função surge quando o cuidador se conscientiza de que o cuidado constitui peça fundamental para a recuperação do idoso.

\section{Discussão}

Observou-se predomínio de cuidadores familiares do sexo feminino, casadas, do lar e com algum grau de parentesco com os idosos - geralmente filhas. Estas características estão associadas ao papel cultural atribuído à mulher em nossa sociedade, que tem como uma de suas principais funções a promoção do cuidado familiar. Este mesmo perfil foi identificado em estudo com idosos dependentes assistidos pela Pastoral da Pessoa Idosa em município do Oeste do Paraná( ${ }^{(7)}$.

Os cuidadores em estudo não fizeram referência ao motivo que os levaram a assumir a função de cuidar, o que permite inferir que ela foi "naturalmente assumida", diferente do que foi encontrado em estudo realizado com cuidadores informais de idosos internados no Hospital Risoleta Tolentino Neves, em Belo Horizonte ${ }^{(8)}$, e também em estudo realizado em Pelotas, no Rio Grande do Sul, com familiares de dois idosos que haviam sofrido queda ${ }^{(9)}$. Em ambos os casos, assumir o cuidado era percebido como um modo de aliviar a culpa pelo processo de adoecimento da pessoa, além de cumprimento de dever.

Em relação aos idosos que sofreram queda, as características encontradas - idade acima de 70 anos, sexo feminino e fratura do fêmur como segmento corporal mais atingido - assemelham-se às de estudo realizado com 14 idosos hospitalizados em decorrência de queda em um hospital geral no Rio Grande do Sul, o qual 
constatou predominância de sexo feminino, cerca de 80 anos, fratura de fêmur decorrente de queda da própria altura, ocorrida durante a realização das atividades de vida diária, e necessidade de tratamento cirúrgico ${ }^{(10)}$. Resultado semelhante foi encontrado em estudo realizado em Portugal com 60 idosos, seis meses após a ocorrência da queda, com o objetivo de identificar a dependência funcional ${ }^{(11)}$.

Foi identificado que os cuidadores familiares estavam satisfeitos com o apoio que receberam para realização do cuidado, bem como com as orientações e a assistência prestada pela equipe de saúde, em especial a de enfermagem, no domicílio, o que pode estar relacionado com a atuação da equipe da ESF. Ademais, observou-se que a relação de proximidade que existia entre os profissionais, os familiares e o idoso facilitou o processo de cuidado e favoreceu a recuperação. É provável que tal fato decorra de o estudo ter sido realizado em um município de pequeno porte, o que possibilita que relações sociais sejam estabelecidas com maior facilidade.

Este resultado é contrário ao encontrado em pesquisa realizado em Pelotas, no Rio Grande do Sul $^{(12)}$, no qual uma das quatro idosas em estudo, vítima de fratura decorrente de queda, afirmou categoricamente ter recebido poucas orientações dos profissionais de saúde e que elas não eram claras; declarou ainda que os profissionais criticavam o que estavam fazendo em casa, mas não explicavam o que tinha que ser feito. Este fato levou os autores a considerarem que, embora as famílias necessitassem de suporte para o enfrentamento da recuperação da saúde do idoso, existia uma lacuna no que a ESF ofertava ${ }^{(12)}$.

Ressalta-se que, no caso deste estudo, os cuidadores também destacaram as orientações realizadas pela equipe de saúde quanto à necessidade de implementação de cuidados e adoção de hábitos para redução dos riscos de novos episódios de quedas e a importância de estratégias para o envelhecimento saudável, o que corrobora resultados de estudo realizado em instituição de longa permanência em Porto Alegre (RS) ${ }^{(13)}$. A identificação precoce dos fatores de risco para quedas, intrínsecos e extrínsecos, também constitui estratégia importante para a prevenção de novos episódios.

O episódio de queda em idosos é uma situação que pode ter consequências importantes. Fraturas graves podem afetar a qualidade de vida não só do idoso acometido, mas também de seus familiares, pois a restrição ao leito ou mesmo a imobilização de um de seus membros desencadeia dependência, o que, consequentemente, afeta a funcionalidade familiar ${ }^{(14)}$.

Ressalta-se que sete dentre os idosos em estudo eram totalmente independentes antes da queda. A perda repentina desta condição - com necessidade de ajuda para a realização de tarefas da vida diária, como o preparo de refeições, limpeza da casa, realização do autocuidado e atendimento de necessidades básicas - constituiu um grande transtorno tanto para o idoso quanto para o familiar que assumiu a função de cuidador.

Ademais, muitas vezes, independentemente do sexo do idoso, alguns cuidados, como a realização do banho e a troca de fraldas, podem causar vergonha e constrangimento para ambos, especialmente nos casos em que a nora cuida do sogro. Nestes casos, os profissionais de saúde podem ajudar a cuidadora a falar com sua família sobre a importância de outras pessoas - a exemplo do filho do idoso -, ajudarem de forma mais efetiva no cuidado, em específico no banho. É mais adequado mudar o horário do banho, de modo que um homem da família possa responsabilizar-se por ele, do que trabalhar sentimentos de vergonha em uma pessoa idosa.

Importante lembrar que o familiar que assume a função de cuidador principal de idoso que sofreu queda quase sempre não está preparado física e/ou emocionalmente para esse enfrentamento. Destaca-se que alguns cuidados exigem mais do que disposição e empenho, sendo necessários força, habilidade e conhecimento específico ${ }^{(12)}$. Neste caso, particularmente, o cuidador precisa aprender a realizar inúmeras tarefas/atividades e, ao mesmo tempo, oferecer apoio afetivo, força e coragem ao idoso, para que este possa lidar com sua condição atual e enfrentar, da melhor maneira possível, 
as limitações decorrentes desta condição. Ele também precisa aprender a lidar com as tensões e esforços decorrentes deste cuidar, cujas implicações dependerá das necessidades de cada família e de quem é cuidado ${ }^{(15)}$.

Esses fatores acarretam sobrecarga física, emocional e social ao cuidador, alterando e limitando sua rotina diária, tal como referido pelos cuidadores em estudo. Estes resultados reafirmam o quanto assumir a responsabilidade pelos cuidados de outra pessoa interfere na vida pessoal e familiar daquele que o faz, independentemente do tipo de situação que gerou a dependência. Nesta direção, estudo realizado com cuidadores de idosos com demência constatou que o tempo dedicado aos cuidados restringe a participação desses em atividades realizadas dentro e fora de casa ${ }^{(16)}$. Esta condição, de certa forma, já é conhecida dos profissionais, visto que estudo realizado com enfermeiras em João Pessoa (PB) constatou que elas consideravam que a sobrecarga adquirida no dia a dia era um dos principais motivos da tensão do papel de cuidador $^{(17)}$.

Nesse contexto, tal como relatado pelos participantes deste estudo, é de grande valia a presença de um profissional de saúde que se preocupe em orientar e apoiar o cuidador para o enfrentamento da rotina diária do cuidado, além de compreender suas necessidades e limitações e valorizar seus esforços. Ações nesta direção poderão propiciar melhora do bem-estar físico e psicológico dos cuidadores familiares, beneficiando não somente a eles, mas também aos que recebem seus cuidados ${ }^{(16)}$.

Ressalta-se que, no caso de fraturas em idosos decorrentes de queda, os cuidados oferecidos no ambiente domiciliar e desenvolvidos pela família são fundamentais para o bem-estar e a qualidade de vida do idoso. Isso porque o cuidado instrumental, quando associado ao apoio afetivo, é indispensável para o enfrentamento das limitações geradas pela queda ${ }^{(8-9)}$. Além disso, entre as particularidades do cuidado ao idoso com fratura, destaca-se a dificuldade de aceitação, por parte desse, em assumir uma situação de dependência não vivenciada antes, assim como a nova rotina a ser adotada.

Estudo realizado em um hospital de grande porte no Rio Grande do Sul, ao avaliar o cuidado da família com o idoso após acidente por quedas, identificou que esta executa um importante papel na recuperação do idoso fragilizado, por oferecer confiança, suporte emocional e auxílio durante a fase de dependência ${ }^{(9)}$.

Ademais, mudanças de atitudes caracterizadas por envolvimento e cooperação por parte de outros membros da família certamente contribuirão para o bem-estar do idoso e sua recuperação. Sendo assim, apesar de haver um membro da família que geralmente assume a maior parte das responsabilidades pelos cuidados, os demais podem e devem compartilhar tarefas, favorecendo a efetividade do funcionamento familiar, visto que o compartilhamento tende a reduzir a sobrecarga física e financeira. Além disso, o envolvimento dos membros da família favorece o apoio entre eles, seja pelo fato de os laços familiares tornarem-se mais estreitos, seja pela busca compartilhada de resoluções de problemas ${ }^{(18)}$.

Outras particularidades desse processo de cuidado são decorrentes das mudanças ocasionadas pela dependência do idoso que interferem na rotina de quem assume o cuidado e até mesmo na de sua família ${ }^{(9)}$, e isto causa sofrimento e a sensação de sobrecarga. De qualquer modo, as mudanças são sempre implementadas com a expectativa de promover melhor qualidade de vida e uma recuperação mais rápida. Destarte, no caso de quedas, a dependência por cuidados, diferentemente do que ocorre nas doenças crônicas, tende a diminuir com o tempo e mesmo deixar de existir. Neste sentido, por mais que o idoso sinta-se debilitado é importante que o cuidador incentive-o a ser protagonista do cuidado, para que sua autonomia seja estabelecida o quanto antes e sustentada no cotidiano ${ }^{(7)}$.

De fato, o convívio com o idoso que sofreu queda e apresenta limitações/restrições no desempenho das atividades básicas diárias pode ser marcado por momentos de grande dificuldade, pois os indivíduos experienciam de forma singular sua complexidade e subjetividade, o 
que os leva a lidar de forma diferente com as limitações impostas por uma condição, ainda que temporária. Sendo assim, os cuidadores precisam desenvolver algumas habilidades com o objetivo de facilitar as atividades no dia a dia, prevenir complicações no estado de saúde do idoso, promover seu bem-estar físico e mental, além de organizar o espaço físico para prevenir futuras quedas. Ademais, torna-se necessário que as ações de cuidado dispensadas pela equipe de saúde sejam estendidas também aos cuidadores/familiares, pois foi observado que a realização dos cuidados constituía prioridade para o cuidador, que relegava a segundo plano seu autocuidado e bem-estar. Esta atitude, ao longo do tempo, pode prejudicar a saúde física e psicológica e, consequentemente, influenciar a forma como o idoso fraturado é cuidado ${ }^{(7)}$.

As unidades de contexto mostraram que os cuidadores buscaram, na religiosidade/espiritualidade, uma forma de conforto para o sofrimento/angústia e alívio da sobrecarga emocional. A relevância da fé e da esperança está no próprio contexto existencial humano, por formar um elo com o Divino, com o outro e com tudo o que o cerca. As famílias ressignificaram a fé no Divino como um suporte e sustento para os momentos de dor e sofrimento causados pela perda de autonomia e dependência do idoso, além de se agarrarem no misticismo e na confiança em Deus, para se sentirem mais seguras diante da realidade de conviver com o idoso fraturado ${ }^{(9)}$.

A religiosidade/espiritualidade faz com que muitos encontrem significado para uma situação negativa ou faça com que a interpretem como um plano maior de Deus. Assim, a religiosidade/ espiritualidade representa, para o cuidador, um mecanismo de enfrentamento capaz de aliviar o estresse físico e mental e, até mesmo, afastar o desejo de desistir e a sensação de derrota/desânimo. Tais dados corroboram resultado de estudo reflexivo sobre a presença da espiritualidade e religiosidade no cotidiano dos profissionais de enfermagem que atuam no ambiente hospitalar. De acordo com os autores, a espiritualidade é um recurso efetivo para gerenciar o cuidado, que tanto pode favorecer quem é cuidado quanto quem cuida ${ }^{(19)}$.

Destaca-se como limitação do presente estudo o fato de ter sido realizado em um município de pequeno porte, o que possibilita que relações sociais sejam estabelecidas com maior facilidade, favorecendo, por exemplo, o vínculo entre os profissionais de saúde e a população. De qualquer modo, os resultados encontrados podem subsidiar reflexões acerca dos elementos envolvidos no processo de cuidado ao idoso após episódio de queda, direcionando, assim, os aspectos a serem considerados na assistência às famílias que enfrentam esta condição.

\section{Conclusão}

$\mathrm{Na}$ perspectiva dos cuidadores familiares em estudo, o cuidado e a recuperação do idoso com fratura decorrente de queda é permeado por dificuldades, em especial pela condição de dependência do idoso, embora por vezes esta seja temporária, pela dificuldade que o idoso tem de aceitar esta condição, pela sobrecarga física e emocional, além das mudanças que ocorrem em seu cotidiano pessoal e familiar.

Os cuidadores percebiam que a recuperação do idoso com fratura decorrente de queda era influenciada pelo esforço empreendido no desempenho do cuidado, com vistas à manutenção das atividades básicas de vida do idoso e sua reabilitação.

Observou-se que, a partir do momento em que o idoso era acometido por uma fratura, dependendo do segmento corporal afetado, sua vida e a dos seus familiares mais próximos, em especial aquele que assumia o papel de cuidador principal, era significativamente alterada. A enfermagem tem papel fundamental nesse contexto, podendo ofertar apoio informacional e instrumental. Por outro lado, o cuidador familiar encontra, na espiritualidade, forças e estímulos para cuidar, pois reconhece que o cuidado ofertado é indispensável não só para a recuperação clínica do idoso, mas também para a sua própria sobrevivência, à medida que é básico, mas também essencial à manutenção da vida. 


\section{Colaborações:}

1 - concepção, projeto, análise e interpretação dos dados: Camila Moraes Garollo e Sonia Silva Marcon;

2 - redação do artigo e revisão crítica relevante do conteúdo intelectual: Camila Moraes Garollo, Sonia Silva Marcon, Elen Ferraz Teston, Helen Cristina Bernardes Barbosa, Josane Rosenilda da Costa, Ivi Ribeiro Back e Patricia Chatalov Ferreira;

3 - aprovação final da versão a ser publicada: Sonia Silva Marcon e Elen Ferraz Teston.

\section{Referências}

1. Nações Unidas. Brasil: OMS cobra melhorias no atendimento aos idosos [Internet]. Brasília (DF); 2017 [cited 2018 Jan 24]. Available from:https://nacoesunidas.org/oms-cobra-melhoriasno-atendimento-aos-idosos/

2. Organización Mundial de la Salud. Caídas: nota descritiva. Ginebra (CH); 2016 [cited 2018 Jan 24]. Available from: http:// www.who.int/mediacentre/ factsheets/fs344/es/

3. Couto AM, Castro EAB, Caldas CP. Vivências de ser cuidador familiar de idosos dependentes no ambiente domiciliar. Rev Rene. 2016 Jan/Fev;17(1):76-85. DOI: 10.15253/2175-6783.2016000100011

4. Pimentel L. Filho és, pai serás... cuidar de pessoas idosas em contexto familiar. Lisboa (PT): Coisas de Ler; 2013.

5. Carvalho MI. Serviço Social com famílias. Lisboa (PT): Pactor; 2015.

6. Bardin L. Análise de conteúdo. Lisboa (PT): Edições 70; 2016.

7. Oliveira MC, Boaretto LM, Vieira L, Tavares KO. Percepção do cuidador familiar de idosos dependentes sobre o papel do profissional da saúde em sua atividade. Semina cienc biol saúde. 2014 Jul/Dez;35(2):81-90. DOI: 10.5433/ 1679-0367.2014v35n2p81

8. Cabral B, Perez NC. Percepções do cuidador familiar sobre o cuidado prestado ao idoso hospitalizado. Rev ter ocup. 2015 abr;26(1):118-27. DOI: https://doi.org/10.11606/issn.2238-6149. v26i1p118-127

9. Pereira-Llano PM, Santos F, Rodrigues MCT, Lemões MAM, Lange C, Santos SSC. The family in the care process of elderly after a fall accident. Rev Fund Care Online. 2016;8(3):4717-24. DOI: http:// dx.doi.org/10.9789/2175-5361.2016

10. Poll AM, Hoffmeister MCA, Tier GC, Santos CSS. Ocorrência de hospitalizações de idosos por quedas. Ciênc cuid saúde. 2014 jul/ set;13(3):447-54. DOI: http://dx.doi.org/10.1590/ 1413-81232018234.09962016

11. Martins R, Mesquita MFP. Fraturas da Extremidade Superior do Fémur em Idosos. Millenium [Internet]. 2016 [cited 2019 Jul 23];50:239-52. Available from: http://www.ipv.pt/millenium/Millenium50/14.pdf

12. Pereira-Llano PM, Lange C, Schwartz E, Meincke SM, Muniz RM, Castro DSP. Família como vínculo apoiador ao idoso após acidentes por quedas: uma abordagem bioecológica à Enfermagem. Rev Kairós: Gerontol [Internet]. 2016 [cited 2019 Dec 18];19(3):257-73. Available from: file:///C:/Users/den/Downloads/3326490062-1-SM\%20(1).pdf

13. Rosa VPP, Cappellari FCBD, Urbanetto JS. Análise dos fatores de risco para queda em idosos institucionalizados Rev bras geriatr gerontol. 2019;22(1):e180138. DOI: http://dx.doi. org/10.1590/1981-22562019022.180138

14. Moura SRB, Marques Junior MASS, Oliveira TA, Nascimento LDS, Mesquita GV, Brito JNPO. Fatores associados à queda de idosos que podem resultar em fratura de fêmur. Rev enferm UFPE on line. 2016 fev;10(2):720-6. DOI: 10.5205/reuol. 6884-59404-2-SM-1.1002sup201604

15. Rocha MPS. A família cuidadora do idoso dependente e o olhar para o cuidador familiar. Rev Portal Divulg [Internet]. 2016 [cited 2019 Dec 19];47:60-7. Available from: https://revistalongeviver.com.br/ index.php/revistaportal/article/viewFile/572/628

16. Carvalho EB, Neri AL. Padrões de uso do tempo em cuidadores familiares de idosos com demências. Rev bras geriatr gerontol. 2019;22(1):e180143. DOI: http://dx.doi.org/10.1590/ 1981-22562019022.180143

17. Loureiro LSN, Pereira MA, Fernandes MGM, Oliveira JS. Percepção de enfermeiras sobre a tensão do papel de cuidador. Rev Baiana Enferm [Internet]. 2015 [cited 2019 Dec 23];29(2):164-71. Available from: https://portalseer.ufba.br/index. php/enfermagem/article/view/12596/pdf_122

18. Cunha JVB, Reiners AAO, Azevedo RCS, Cardoso JDC, Cunha CRT, Silva KM. Funcionamento de famílias com idosos totalmente dependentes. 
Ciênc Cuid Saúde. 2019;18(2):e48825. DOI: https:// doi.org/10.4025/cienccuidsaude.v18i2.48825

19. Tavares MDM, Gomes AMT, Barbosa DJ, Rocha JCCD, Bernardes MMR, Thiengo PCDS. Espiritualidade e religiosidade no cotidiano de enfermagem hospitalar. Rev Enferm UFPE on line.
2018;12(4):1097-102. DOI: 10.5205/1981-8963-v12i 4a234371p129-139-2018

Recebido: 2 de dezembro de 2019

Aprovado: 11 de fevereiro de 2020

Publicado: 9 de abril de 2020

A Revista Baiana de Enfermagem utiliza a Licença Creative Commons - Atribuição-NãoComercial 4.0 Internacional. https://creativecommons.org/licenses/by-nc/4.0/

Este artigo é de acesso aberto distribuído sob os termos da Licença Creative Commons (CC BY-NC). Esta licença permite que outros remixem, adaptem e criem a partir do seu trabalho para fins não comerciais. Embora os novos trabalhos tenham de lhe atribuir o devido crédito e não possam ser usados para fins comerciais, os usuários não têm de licenciar esses trabalhos derivados sob os mesmos termos. 